
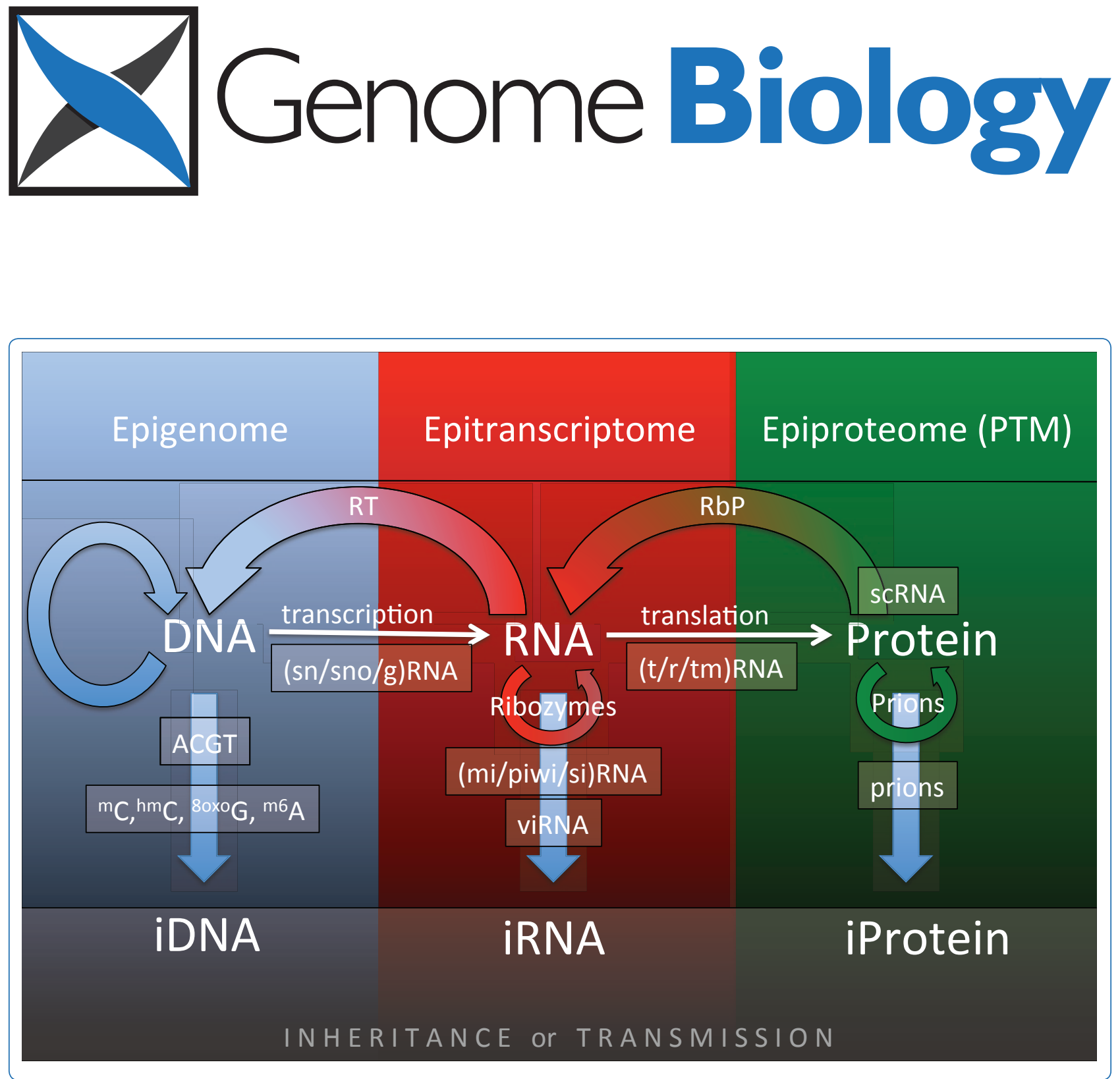

\title{
The birth of the Epitranscriptome: deciphering the function of RNA modifications
}

Yogesh Saletore, Kate Meyer, Jonas Korlach, Igor D Vilfan, Samie Jaffrey and Christopher E Mason 


\section{The birth of the Epitranscriptome: deciphering the function of RNA modifications}

Yogesh Saletore ${ }^{1,2,3}$, Kate Meyer ${ }^{4}$, Jonas Korlach5, Igor D Vilfan ${ }^{5}$, Samie Jaffrey ${ }^{4}$ and Christopher E Mason ${ }^{1,2, *}$

\begin{abstract}
Recent studies have found methyl-6-adenosine in thousands of mammalian genes, and this modification is most pronounced near the beginning of the $3^{\prime} U T R$. We present a perspective on current work and new single-molecule sequencing methods for detecting RNA base modifications.
\end{abstract}

Keywords epigenetics, epigenomics, epitranscriptome, $\mathrm{m}^{6} \mathrm{~A}$, methyl-6-adenosine, methyladenosine, N6methyladenosine, RNA modifications

\section{Introduction}

Techniques for sequencing RNA and DNA pioneered by Fred Sanger and others in the 1960s [1] and 1970s [2] began to reveal the biochemical recipes for storing biological information in organisms and laid the foundation for modern genomics. Yet, decades before the first nucleic acid was sequenced, various chemical modifications of DNA had already been described, such as 5-methylcytosine [3] and 5-hydroxy-methylcytosine [4], now dubbed the 5th [5] and 6th [6] base of genetics; in total, several dozen DNA modifications have been reported [7]. These modifications, along with histone modifications, are now recognized as important regulatory mechanisms for controlling gene expression and function [8].

Fortunately, it is now relatively easy to characterize these modified DNA bases, which form part of the 'epi'genome (epi, on top), for any organism with a finished genome, given the widespread availability of highthroughput techniques, especially those based on nextgeneration sequencing (NGS). Various NGS approaches are being used in the National Institutes of Health (NIH)'s Epigenomics Roadmap [9] and in the BLUEPRINT

*Correspondence: chm2042@med.cornell.edu

'Department of Physiology and Biophysics, Weill Cornell Medical College, New York, NY 10065, USA

Full list of author information is available at the end of the article
Project [10]. Similarly, cell-specific, post-translational modifications of proteins, sometimes referred to collectively as the 'epiproteome' [11], are essential mechanisms necessary for the regulation of protein activity, folding, stability and binding partners. Elucidating the roles of protein and DNA modifications has had a major impact on our understanding of cellular signaling, gene regulation and cancer biology [12].

However, our understanding of an additional regulatory layer of biology that rests between DNA and proteins is still in its infancy; namely, the multitude of RNA modifications that together constitute the 'Epitranscriptome'. There are currently 107 known RNA base modifications, with the majority of these having been reported in tRNAs or rRNAs [13]. Outside the 5' cap, the role of modifications in mRNA is unclear $[14,15]$. One RNA modification, N6-methyladenosine, or methyl-6-adenosine $\left(\mathrm{m}^{6} \mathrm{~A}\right)$, has been observed in a wide variety of organisms, including viruses [16], yeast [17], plants [18], humans [19,20] and mice $[19,20]$, and exhibits dynamic changes in response to a variety of stimuli in yeast [21]. Older studies using purified polyadenylated RNA from mammalian cells showed that $\mathrm{m}^{6} \mathrm{~A}$ was the most abundant post-transcriptional modification in polyadenylated RNA [14], which contemporary doctrine considered to be synonymous with mRNA. However, it is now known that polyadenylation occurs not only on mRNAs, but also in other RNAs, such as rRNAs and long intergenic noncoding RNAs (lincRNAs). Thus, it was historically unclear exactly how $\mathrm{m}^{6} \mathrm{~A}$ existed in mRNAs and, if so, whether it was restricted to a select few transcripts or prevalent throughout the transcriptome.

Previous methods for investigating the prevalence of $\mathrm{m}^{6} \mathrm{~A}$ were laborious and involved incubating cells with ${ }^{14} \mathrm{C}$-radiolabeled methionine (the precursor for the endogenous methyl donor, $S$-adenosylmethionine), following which the incorporation of methyl groups into RNAs could be quantified. These early studies detected methylated bases in ribosomal RNA (rRNA) [22], small RNA fractions [23-27] and in mRNAs [28]. However, these methods were limited by their inability to identify the specific mRNAs that contained $\mathrm{m}^{6} \mathrm{~A}$. Indeed, $\mathrm{m}^{6} \mathrm{~A}$ had previously been detected in vivo for only a single 
mammalian mRNA (bovine prolactin [29]), and the specific sites of $\mathrm{m}^{6} \mathrm{~A}$ incorporation had been established for only two RNAs: prolactin [29] and Rous sarcoma virus RNA [30,31]. The methods used to map these $\mathrm{m}^{6} \mathrm{~A}$ sites were technically challenging and, more importantly, required a pre-ordained focus on a particular transcript, rather than a global approach that could detect sites of adenosine methylation in all mRNAs. Moreover, adenosine methylation is invisible, insofar as both methylated and non-methylated adenosines readily base pair with $\mathrm{T}$ or $\mathrm{U}$, and both are reverse transcribed to $\mathrm{T}$, further hindering the study of $\mathrm{m}^{6} \mathrm{~A}$ and its role in biology.

However, a renewed interest in $\mathrm{m}^{6} \mathrm{~A}$ has recently emerged, partially due to the finding that the fat massand obesity-associated (FTO) gene encodes a brain- and hypothalamus-enriched $\mathrm{m}^{6} \mathrm{~A}$ demethylase that is responsible for converting $\mathrm{m}^{6} \mathrm{~A}$ to adenosine [32]. Defects in this enzyme result in significant alterations in energy use and metabolism, and mutations in FTO have recently been linked to a higher risk for Alzheimer's disease and decreased brain mass $[33,34]$. These studies suggest that $\mathrm{m}^{6} \mathrm{~A}$ may have a physiological role in cellular signaling and neurodegeneration. Recent advances in NGS technology, in addition to the availability of antibodies that recognize $\mathrm{m}^{6} \mathrm{~A}$, have enabled the development of global approaches for studying $\mathrm{m}^{6} \mathrm{~A}$. Recently, two groups have independently developed high-throughput methods for rapid characterization of $\mathrm{m}^{6} \mathrm{~A}$ sites across the transcriptome. Methods such as methyl-RNA-immunoprecipitation-sequencing (MeRIP-seq) [19] or $\mathrm{m}^{6} \mathrm{~A}$-seq [20], which combine immunoprecipitation (IP) of methylated RNAs using an $\mathrm{m}^{6} \mathrm{~A}$-specific antibody, with NGS, have finally opened the door to global methods for studying the epitranscriptome and its dynamics.

\section{Mapping the epitranscriptome}

Although MeRIP-seq and $\mathrm{m}^{6} \mathrm{~A}$-seq were developed independently $[19,20]$, both are very similar in the initial RNA preparation and IP steps. The larger differences between the two protocols lie in their downstream computational methods rather than in sample preparation, which in both cases followed methods similar to existing chromatin IP-seq (ChIP-seq), insofar as they performed IP with an $\mathrm{m}^{6} \mathrm{~A}$-specific antibody. Table 1 shows the similarities and differences between the MeRIP-seq and $\mathrm{m}^{6} \mathrm{~A}$-seq protocols.

Both datasets produced qualitatively similar results, with $\mathrm{m}^{6} \mathrm{~A}$ peaks in introns, 5 ' UTRs, exons, splice junctions, ncRNAs and intergenic regions, indicating that $\mathrm{m}^{6} \mathrm{~A}$ is a widespread and wide-ranging RNA modification. The MeRIP-seq study also identified peaks in lincRNAs. The genomic features for which $\mathrm{m}^{6} \mathrm{~A}$ was particularly enriched are listed in Table 1; the main discrepancy between the two studies in this regard concerned the enrichment of $\mathrm{m}^{6} \mathrm{~A}$ at transcription start sites (TSSs), which was observed by $\mathrm{m}^{6} \mathrm{~A}$-seq, primarily in a single cell line (Figure 1a). An explanation for this discrepancy may be the different window used to define the TSS. A comparison between mouse and human data in both studies showed a high conservation of specific $\mathrm{m}^{6} \mathrm{~A}$ sites across the two species. Finally, digesting samples with various RNases prior to MeRIP-seq demonstrated that $\mathrm{m}^{6} \mathrm{~A}$ sites were mostly present at internal sites within mRNAs and were absent from polyA tails.

In addition to sequencing, the MeRIP-seq study also used immunoblotting to investigate $\mathrm{m}^{6} \mathrm{~A}$, demonstrating that $\mathrm{m}^{6} \mathrm{~A}$ is present in mouse heart, lung, brain, liver and kidney tissues, with a particular enrichment in brain, liver and kidney. High levels of $\mathrm{m}^{6} \mathrm{~A}$ were found in HepG2 and MCF7 cells, in contrast to lower levels detected in other human cancer cell lines (PC3 and PC9). The dynamic nature of $\mathrm{m}^{6} \mathrm{~A}$ was confirmed by comparing embryonic with adult tissue, which showed that $\mathrm{m}^{6} \mathrm{~A}$ levels increase over the course of development. The $\mathrm{m}^{6} \mathrm{~A}$ seq study also found $\mathrm{m}^{6} \mathrm{~A}$ to be a dynamic modification, finding that its distribution changed in response to a variety of external stimuli (ultraviolet, interferon gamma, hepatocyte growth factor and heat shock), although as many as 70 to $95 \%$ of the peaks were static.

Experiments leveraging the depletion of the METTL3 subunit responsible for methylating adenosines were used in the $\mathrm{m}^{6} \mathrm{~A}$-seq study to explore the modification's function. A statistically significant increase in the abundance of alternatively spliced transcripts was observed as a result of this depletion, with the alternatively spliced exons and introns showing an enrichment for $\mathrm{m}^{6} \mathrm{~A}$ peaks. However, a permutation analysis of splice junctionlocalized $\mathrm{m}^{6} \mathrm{~A}$ sites in the MeRIP-seq study data did not find a statistically significant enrichment of $\mathrm{m}^{6} \mathrm{~A}$ peaks in the proximity of splice junctions [19]. Moreover, an analysis of the total mapped bases from the MeRIP-seq samples versus the control, non-IP RNA samples showed that fewer bases mapped to splice junctions in the IP samples (Additional file 1). Elucidating whether $\mathrm{m}^{6} \mathrm{~A}$ functions in splicing and, if so, whether this is direct or indirect through the regulation of splicing factorencoding transcripts, will require further investigation. In light of the MeRIP-seq data, we suggest that $\mathrm{m}^{6} \mathrm{~A}$ is not likely to cause an overall increase in the global amount of transcript splicing, but it may modify splicing for certain classes of genes, and particularly for genes with alternative, internal exons [20].

\section{Challenges of epitranscriptomic site detection}

There are many factors to consider when computing the $\mathrm{m}^{6} \mathrm{~A}$ enrichment for a site. For example, the definition of gene regions, the gene isoform used, the presence of secondary structure, the alignment method and the read 
Table 1. Comparison of MeRIP-seq and $\mathrm{m}^{6} \mathrm{~A}$-seq

\begin{tabular}{|c|c|c|c|c|c|}
\hline \multirow[b]{2}{*}{ Tissue/cell line } & \multicolumn{2}{|c|}{ MeRIP-seq [19] } & \multicolumn{3}{|c|}{$\mathrm{m}^{6} \mathrm{~A}$-seq $[20]$} \\
\hline & C57BL/6 brain & HEK293T & & HepG2 & C57BL/6 liver \\
\hline Organism & Mouse & Human & & Human & Mouse \\
\hline Replicates (n) & \multicolumn{2}{|c|}{3} & \multicolumn{3}{|c|}{1} \\
\hline RNA preparation & \multicolumn{2}{|c|}{ RiboMinus } & \multicolumn{3}{|c|}{ GenElute mRNA } \\
\hline IP antibody & \multicolumn{2}{|c|}{ Synaptic Systems, NEB } & & \multicolumn{2}{|c|}{ Synaptic Systems } \\
\hline IP rounds (n) & \multicolumn{2}{|c|}{2} & & \multicolumn{2}{|c|}{1} \\
\hline RNA fragment size & \multicolumn{5}{|c|}{$100 \mathrm{bp}$} \\
\hline RNA sequencing platform & Illumina GAll and HiSeq2000 & Illumina HiSeq2000 & & \multicolumn{2}{|c|}{ Illumina GAll } \\
\hline Sequenced control & \multicolumn{5}{|c|}{ Yes } \\
\hline Aligners & \multicolumn{2}{|c|}{ BWA [38], TopHat [39] } & \multicolumn{3}{|c|}{ Novoalign [70], BowTie [71] } \\
\hline Peak-finder & \multicolumn{2}{|c|}{ MeRIPPeR $[19,35]$} & \multicolumn{3}{|c|}{ Proprietary [20] } \\
\hline Peak-finding algorithm & \multicolumn{2}{|c|}{ Fisher's exact test of IP read enrichment } & \multicolumn{3}{|c|}{ Computed Winscore $>2$ ( $4 \times$ enrichment) + filtering [20] } \\
\hline Peaks reported (n) & 13,471 & 18,756 & & 12,769 & 4,513 \\
\hline Genes/transcripts reported & 4,654 genes & 5,768 genes & & 7,240 transcripts & 3,442 transcripts \\
\hline Peak enrichment & \multicolumn{2}{|c|}{ Stop codon, internal exons } & \multicolumn{3}{|c|}{ Stop codon, TSS, internal exons, AS exons } \\
\hline
\end{tabular}

depth can all impact the degree of enrichment discovered. Given that epitranscriptomics is a nascent field, computational analysis methods are only now emerging. Here, we explore the impact of these factors on detecting and quantifying $\mathrm{m}^{6} \mathrm{~A}$.

A comparison of the raw peaks found in the MeRIP-seq and $\mathrm{m}^{6} \mathrm{~A}$-seq studies showed surprisingly little overlap, even with a single base threshold (Table 2). However, the different cell types used, as well as slightly different RNA handling methods, likely account for some of these peak differences $[19,20]$. Another technical contributor to the low overlap may be erroneous methylation calls, given that the false discovery rate (FDR) for both methods was 5 to $7 \%$. The overlap notably improved when bases in transcripts with low expression levels were excluded (Table 3). These complications notwithstanding, the total number of $\mathrm{m}^{6} \mathrm{~A}$ sites identified encompassed the majority of human genes and almost one-third of mouse genes (Table 2).

We re-analyzed the datasets from both studies in order to determine the effect of the peak-calling method on the apparent $\mathrm{m}^{6} \mathrm{~A}$ distribution in the transcriptome and found two discrepancies. By comparing peak-calling methods, we observed that the presence of the 5 ' UTR peak in the $\mathrm{m}^{6} \mathrm{~A}$-seq dataset was attenuated when that study's peak-caller was replaced by MeRIPPeR [35] from the MeRIP-seq study. This reduction indicates that each of the two peak-calling algorithms may have different sensitivities and specificities.
We also note that the $5^{\prime}$ UTR $\mathrm{m}^{6} \mathrm{~A}$ signal in the original peak sets used a definition of a TSS that was $150 \mathrm{bp}$, and that the signal was primarily derived from larger genes, as measured by exon number (Figure 2); a potential $\mathrm{m}^{6} \mathrm{~A}$ enrichment within these genes can be seen at the end of the first intron and at the beginning of the following exon (Figure 2). Since the distribution of the $\mathrm{m}^{6} \mathrm{~A}$ sites is nonuniform (in the sense that enrichment is dependent on the number of exons in a gene and that on the context of an exon within a gene), a useful method to examine $\mathrm{m}^{6} \mathrm{~A}$ localization, or any epitranscriptomic change, may be to separate the genes into their sub-geographies (Figure 3).

\section{$\mathrm{m}^{6} \mathrm{~A}$ mapping is heavily impacted by the read depth and by the choice of peak detection and alignment methods}

To further investigate the analytic dependency of $\mathrm{m}^{6} \mathrm{~A}$ peak detection, we examined the $\mathrm{m}^{6} \mathrm{~A}$ site detection as a function of alignment method, antibody and read depth. Part of the challenge of MeRIP-seq analysis is a reliance on other IP-seq analysis methods, developed for chromatin IP-seq (ChIP-seq). ChIP-seq experiments are designed to characterize DNA-histone and DNAtranscription factor interactions. Existing ChIP-seq peakfinders take advantage of inherent properties of the data to assist in finding peaks, many of which do not apply in the case of finding $\mathrm{m}^{6} \mathrm{~A}$ sites in RNA. For example, each fragmented RNA molecule pulled-down by an $\mathrm{m}^{6} \mathrm{~A}$ antibody has the potential to harbor far more methylation 


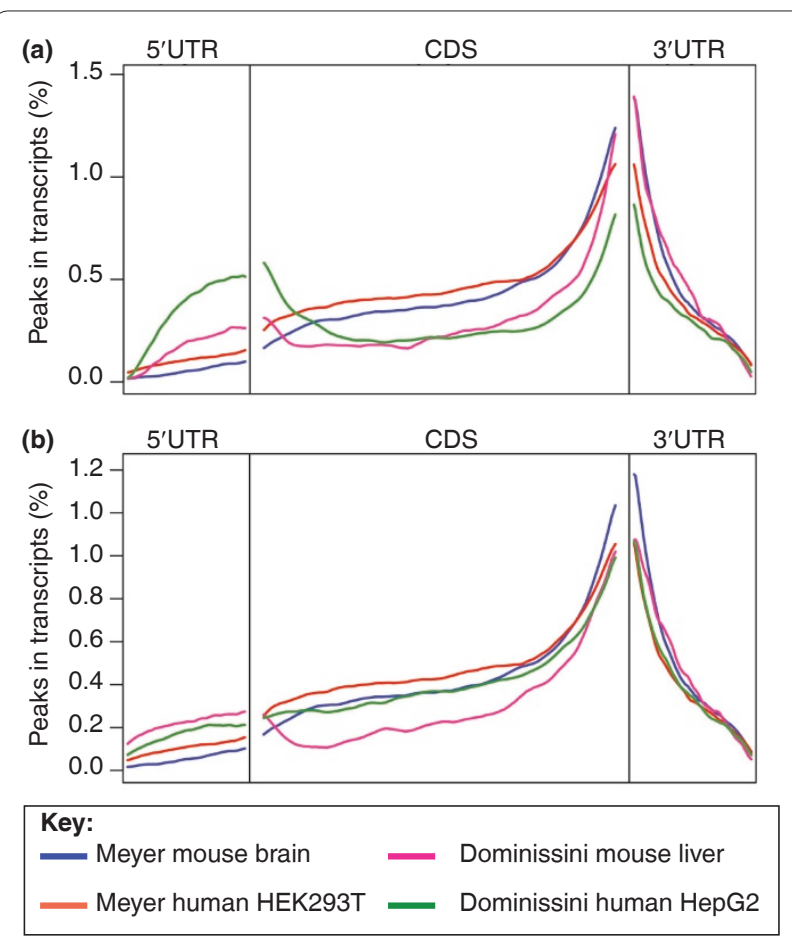

Figure 1. Peak distribution. (a) We plotted the distribution of the peaks reported across gene bodies by the MeRIP-seq and $\mathrm{m}^{6} \mathrm{~A}$ seq studies. Note the very well defined enrichment for peaks near the stop codon and in the $3^{\prime}$ UTR. The $m^{6} \mathrm{~A}$-seq HepG2 peaks also show a peak in the $5^{\prime}$ UTR. (b) The distribution of peaks across the transcriptome using the BWA-based MeRIPPeR pipeline [35] on the data from both groups. Data from [19] and [20]. CDS, coding sequence.

sites than the maximum number of protein binding sites expected for the equivalent ChIP-seq fragment, and so the $\mathrm{m}^{6} \mathrm{~A}$ sites are more challenging to resolve. ChIP-seq peak finders use different methods and heuristics to find peaks, attempting to balance finding weak peaks with maintaining a low FDR and resulting in a diverse group of peak sets $[36,37]$. The same is true for $\mathrm{m}^{6} \mathrm{~A}$ peaks, as the MeRIP-seq study used Fisher's exact test and the $\mathrm{m}^{6} \mathrm{~A}$ seq study derived a window score based on peak enrichment.

Each of the multiple methods for aligning reads to a transcriptome has its own set of advantages and challenges. A genome-based aligner, such as BWA [38], can be used when a genome sequence is available, but introduces added complexity when reads map to multiple transcript variants, and suffers from being unable to align reads to genomic regions that are absent from a predefined reference. Alternatively, a gap-based aligner, such as TopHat [39] or GSNAP [40], can be used, with the advantage that these algorithms are designed for transcriptomes and so can map reads across both known and novel splice junctions. However, these methods tend to
Table 2. Overlap of genes with $\mathbf{m}^{6} \mathrm{~A}$ peaks

\begin{tabular}{lcccc}
\hline Organism & $\begin{array}{c}\text { Total genes } \\
\text { with } \mathbf{~ m}^{6} \mathbf{A}\end{array}$ & $\begin{array}{c}\text { Common } \\
\text { genes }\end{array}$ & $\begin{array}{c}\text { MeRIP-seq } \\
\text { only }\end{array}$ & $\begin{array}{c}\mathbf{m}^{6} \mathbf{A}-\mathbf{s e q} \\
\text { only }\end{array}$ \\
\hline Human & 15,160 & 4,808 & 3,249 & 7,103 \\
Mouse & 7,627 & 2,031 & 3,870 & 1,726 \\
\hline
\end{tabular}

The total number of genes that overlap with $\mathrm{m}^{6} \mathrm{~A}$ sites in at least one of the two datasets ('total genes with $\mathrm{m}^{6} \mathrm{~A}$ ') is shown for both human and mouse. The overlap between the two datasets ('common genes') is small. The number of genes reported in one dataset only for each of the datasets is also shown.

Table 3. Overlap of commonly expressed genes with $\mathrm{m}^{6} \mathrm{~A}$ sites

\begin{tabular}{lccccc}
\hline & $\begin{array}{c}\text { Genes } \\
\text { expressed }\end{array}$ & $\begin{array}{c}\text { Expressed } \\
\text { genes with } \\
\text { Organism } \\
(\mathbf{R P K M} \geq \mathbf{0 . 2 )}\end{array}$ & $\begin{array}{c}\mathbf{m}^{\mathbf{6}} \mathbf{A} \\
\text { Common } \\
\text { genes }\end{array}$ & $\begin{array}{c}\text { MeRIP- } \\
\text { seq only }\end{array}$ & $\begin{array}{c}\mathbf{m}^{\mathbf{6}} \mathbf{A} \text {-seq } \\
\text { only }\end{array}$ \\
Mouse & 19,621 & 7,228 & 3,568 & 1,212 & 2,448 \\
\hline
\end{tabular}

The total number of genes, excluding those with low expression (RPKM $<0.2)$, that overlap with $\mathrm{m}^{6} \mathrm{~A}$ sites in at least one of the two datasets ('expressed genes with $\mathrm{m}^{6} \mathrm{~A}^{\prime}$ ) is shown for both human and mouse. The overlap between the two datasets ('common genes'), as a proportion of the total number of expressed genes with $\mathrm{m}^{6} \mathrm{~A}$, is much higher than the proportion shown in Table 2.

be slower and can introduce many false splice sites, leading to poorly aligned reads. The ability of an aligner to handle errors typical of RNA-seq, which differ to those seen in DNA sequencing, is another factor to consider. A common source of error in RNA-seq is the random hexamer priming used in cDNA synthesis, which introduces a bias in the nucleotide distribution at the beginning of reads [41]. One possible solution to this particular error is to trim the reads, an approach that was employed in the $\mathrm{m}^{6} \mathrm{~A}$-seq study.

To examine the effect of aligner on the detection of $\mathrm{m}^{6} \mathrm{~A}$ peaks, we analyzed processed HEK293T MeRIP-seq data using three aligners (BWA [38], TopHat 2 [39] and GSNAP [40]), and then called peaks with MeRIPPeR [35]. We observed a slight increase in the number of 5 ' UTR peaks when using the transcriptome aligners GSNAP and TopHat 2 relative to the number called when using BWA (Additional file 2). More importantly, there was a significant increase in the number of individual peaks: MeRIPPeR found 19,617 peaks using BWA, 45,738 with GSNAP and 135,706 using TopHat 2, all at the same FDR (0.05). These results indicate that the alignment method selected has a significant impact on the number of peaks identified in a MeRIP-seq dataset.

To effectively gauge the influence of read depth on $\mathrm{m}^{6} \mathrm{~A}$ site detection, we used a sub-sampling titration analysis of the aligned reads. We found that peak detection is heavily dependent on read depth (Additional file 3a), with some aligners showing a nearly linear increase in peaks as a function of depth. The number of genes in which these peaks were found also increased with read depth, albeit less dramatically (Additional file 3b), with 


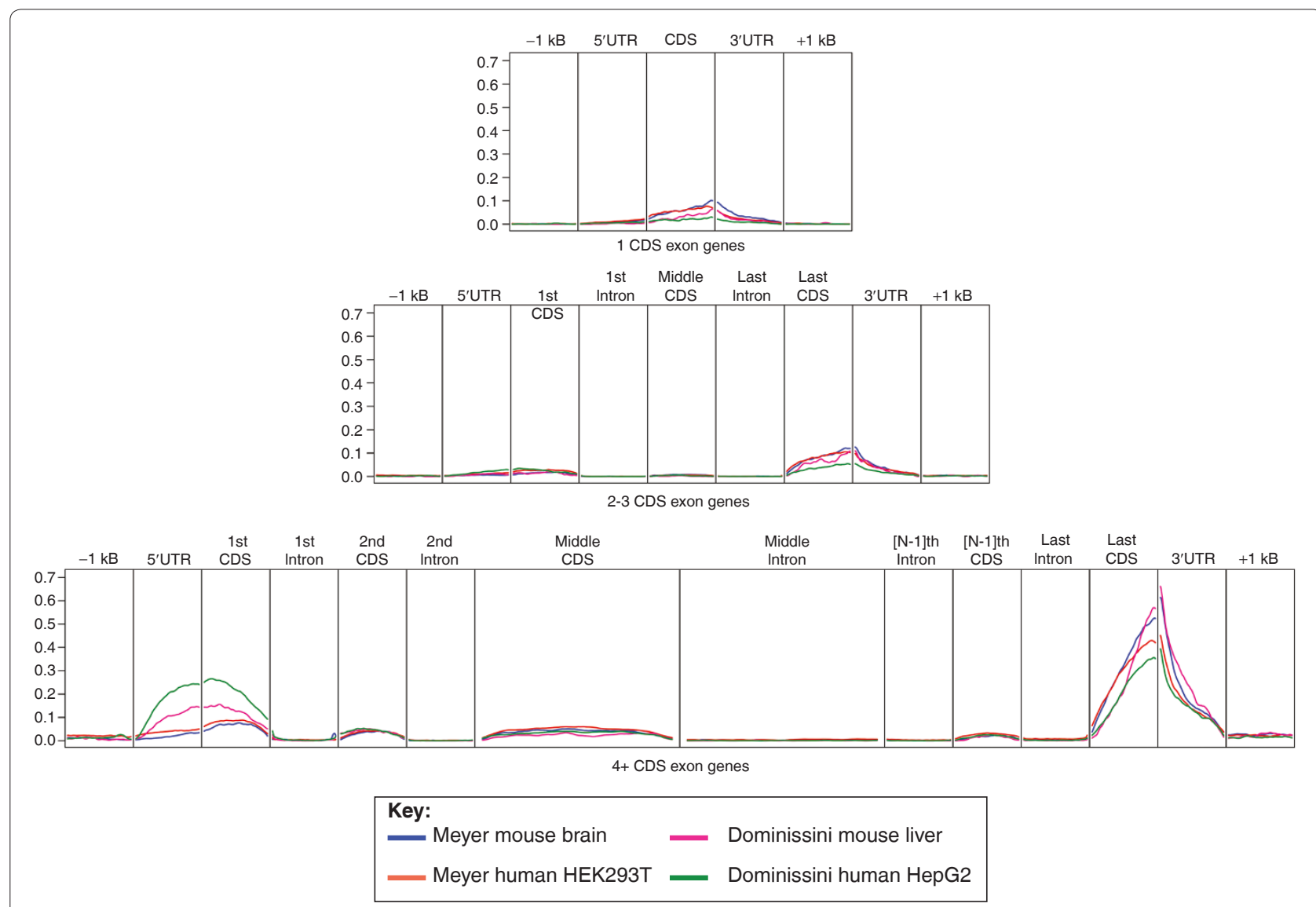

Figure 2. Peak distribution across the transcriptome. The peak distribution depicted is the average across the entire transcriptome. Peaks are mapped to transcripts and assigned to the following transcriptomic features: $1 \mathrm{kB}$ upstream from the TSS and downstream from the transcription end site, $5^{\prime}$ and $3^{\prime}$ UTRs, coding segments (CDS), and exon and intron segments. In the bottom row, peaks mapping to transcripts with four or more exons are shown, with the first, penultimate and last exons separated into individual boxes, as are their neighboring introns. The remaining exons and introns are shown in the middle boxes as a contiguous segment. Genes with only two or three exons are shown in the middle row and single exon genes are shown in the top row. Data from [19] and [20].

the number of genes continually increasing as a function of depth. While a specific point in a transcript might be correctly called as an $\mathrm{m}^{6} \mathrm{~A}$ site, it is not known if the site is methylated in all copies of that transcript [19]. The percentage of transcripts at which a site is methylated may be quantified as the stoichiometry of $\mathrm{m}^{6} \mathrm{~A}$. It is likely that the new peaks detected with increasing read depth are low in $\mathrm{m}^{6} \mathrm{~A}$ stoichiometry and hence more challenging to detect at lower read depths. From these data, we extrapolate that, given enough tissues, cell types and conditions, it is possible that almost all genes may be marked, at some point, by $\mathrm{m}^{6} \mathrm{~A}$.

We next sought to establish whether $\mathrm{m}^{6} \mathrm{~A}$ peak calls vary with the antibody used, by separately plotting peaks obtained with the two different antibodies in the MeRIPseq study. Both antibodies had the same peak distribution across gene bodies (Additional file 4), indicating that the choice of antibody, at least for the two tested, should not impact the global distribution of $\mathrm{m}^{6} \mathrm{~A}$ sites.

\section{$\mathrm{m}^{6} \mathrm{~A}$ motif analysis}

A primary motif [AG]ACU was discovered within $\mathrm{m}^{6} \mathrm{~A}$ peaks by both studies, each of which used a different motif-finding algorithm, and both analyses suggest that the $\mathrm{A}$ in the canonical motif is the methylated site agreeing with prior work in $\mathrm{m}^{6} \mathrm{~A}$ sequence specificity $[42,43]$. Both groups found the motif to be highly enriched in peak regions compared with negative control regions. If the $\mathrm{A}$ in the motif is indeed the $\mathrm{m}^{6} \mathrm{~A}$, then application of this information to $\mathrm{m}^{6} \mathrm{~A}$-seq or MeRIP-seq datasets could enable the mapping of $\mathrm{m}^{6} \mathrm{~A}$ sites at single base pair resolution. We used a motif pattern-matching algorithm from FIRE [44] to find the [AG]ACU motif in the MeRIP-seq mouse dataset (Methods), and subsequently applied the assumption that the $\mathrm{A}$ in each motif is equivalent to an $\mathrm{m}^{6} \mathrm{~A}$ site, to identify $\mathrm{m}^{6} \mathrm{~A}$ sites in all the datasets. We identified 21,004 $\mathrm{m}^{6} \mathrm{~A}$ sites from 10,488 $\mathrm{m}^{6} \mathrm{~A}$-seq HepG2 peaks, 46,293 from 17,071 MeRip-seq HEK293T peaks, 9,124 from 4,054 $\mathrm{m}^{6} \mathrm{~A}$-seq mouse liver 


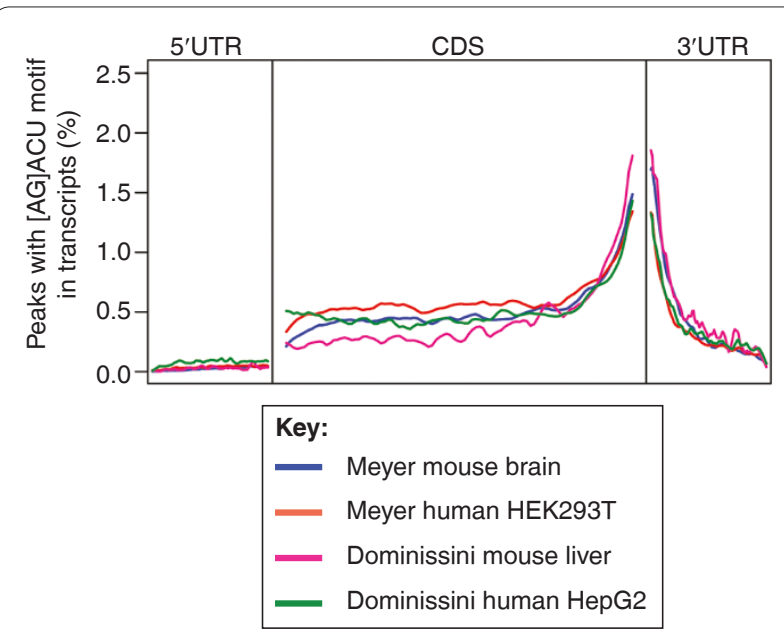

Figure 3. Distribution of [AG]ACU motif sites. The [AG]ACU motif was used to find potential $\mathrm{m}^{6} \mathrm{~A}$ sites within peaks, and the distribution of these potential sites across gene bodies plotted. Data from [19] and [20].

peaks, and 37,459 from 12,664 MeRIP-seq mouse brain peaks. Only about 5 to $15 \%$ of the peaks lacked the motif sequence and the distribution of these putative single base-resolution $\mathrm{m}^{6} \mathrm{~A}$ sites across gene bodies is very similar to the peak distribution (Figure 1a).

However, we did not observe an enrichment of $\mathrm{m}^{6} \mathrm{~A}$ sites in the 5' UTR, and the coding sequence profile is fairly flat until the peak reaches the proximity of the stop codon. This could indicate that the identified [AG]ACU motif is specific to those peaks near the stop codon, or that the peak enrichment near the 5' UTR does not reflect a true increase in the number of actual $\mathrm{m}^{6} \mathrm{~A}$ sites. To test whether the motif was specific to stop codonproximal regions, we performed a FIRE [44] motif finder analysis of the 5' UTR peaks that were present in the MeRIP-seq mouse liver dataset, since this dataset was not enriched for this motif in this genomic region. Nonetheless, FIRE found a [CG]ACU motif, though not the strongest motif, indicating that it is not specific to the stop codon peaks, and thus likely a global motif for $\mathrm{m}^{6} \mathrm{~A}$, but perhaps weakly represented in the 5' UTR.

\section{Single-molecule approaches to RNA modifications}

Single-molecule sequencing has the potential to provide base-level resolution of $\mathrm{m}^{6} \mathrm{~A}$ sites, without the need for motif-based inference. The most commonly found platform for this method of sequencing currently on the market is the single-molecule, real-time (SMRT) technology (Pacific Biosciences). SMRT sequencing uses thousands of zero-mode waveguides (ZMWs) to capture an enzyme in real time, traditionally a DNA polymerase, as it incorporates fluorescent nucleotides into a polymer [45]. This method of molecular monitoring has the advantage of detecting both genetic and epigenetic information simultaneously, since the patterns of base incorporation by the polymerase are contingent upon the steric and sequence contexts of the bases present in the template [46]. Specifically, if a modified base is present on the template, the biophysical dynamics of DNA polymerase movement and base incorporation are affected, creating a unique kinetic signature before, during and after base incorporation, and thus enabling identification of specific DNA modifications [47].

Here, we report a novel application of this technology, which can be used to detect modified bases within RNA, including $\mathrm{m}^{6} \mathrm{~A}$ sites. To characterize $\mathrm{m}^{6} \mathrm{~A}$ sites in RNA at single-nucleotide resolution, we used a reverse transcriptase as the enzyme within a ZMW, instead of a DNA polymerase, and this substitution allowed the direct observation of cDNA synthesis in real time. While base incorporations during reverse transcription typically occur at standard speeds, the incorporation of synthetically designed $\mathrm{m}^{6} \mathrm{~A}$ sites showed that there is a significant increase in the inter-pulse duration (IPD) when a methylated adenosine is present in the RNA template, relative to the IPD for a standard adenosine (Figure 4). To our knowledge, this represents the first demonstration of a reverse transcriptase-based kinetic signature that can directly detect modified RNA. However, current singlemolecule technology is not without its own challenges. First and foremost, reverse transcriptases stutter when incorporating bases, complicating the accurate reading of homonucleotide stretches and the base resolution of $\mathrm{m}^{6} \mathrm{~A}$ therein. Second, the current throughput is too low for transcriptome-wide approaches. Notwithstanding these caveats, the SMRT technology has the clear potential to detect an underlying epitranscriptomic change in a native RNA template.

Similarly, Oxford Nanopore Technologies (ONT) and other companies are developing nanopore-based sequencing technologies, which use nanopore-forming proteins to sequence DNA by attaching an application-specific integrated circuit to the membrane upon which the nanopore rests. In principle, observations of any modified DNA or RNA base could be made during transit of the molecule through the nanopore, and some observations have already been made with nanopores that allow detection of $5 \mathrm{hmC}$ [48]. While all of these technologies are still under development, we note that all directobservation methods, in principle, have the potential to detect $\mathrm{m}^{6} \mathrm{~A}$ and other epitranscriptomic modifications.

\section{Beyond $\mathrm{m}^{6} \mathrm{~A}$ : mapping the full epitranscriptome}

As mentioned previously, $\mathrm{m}^{6} \mathrm{~A}$ is only one of many known epitranscriptomic modifications, the majority of which are located in tRNA and rRNA transcripts. We used data from the RNA Modification Database to 
(a) DNA primer: GCGCTAAGTATACCAGGTTGTG
RNA Template $3^{\prime}$-TGATCCTAGATCGCGATTCATATGGTCCAACACTTAGAACGTCACAAATC-5' CDNA $5^{\prime}-$ AATCTTGCA

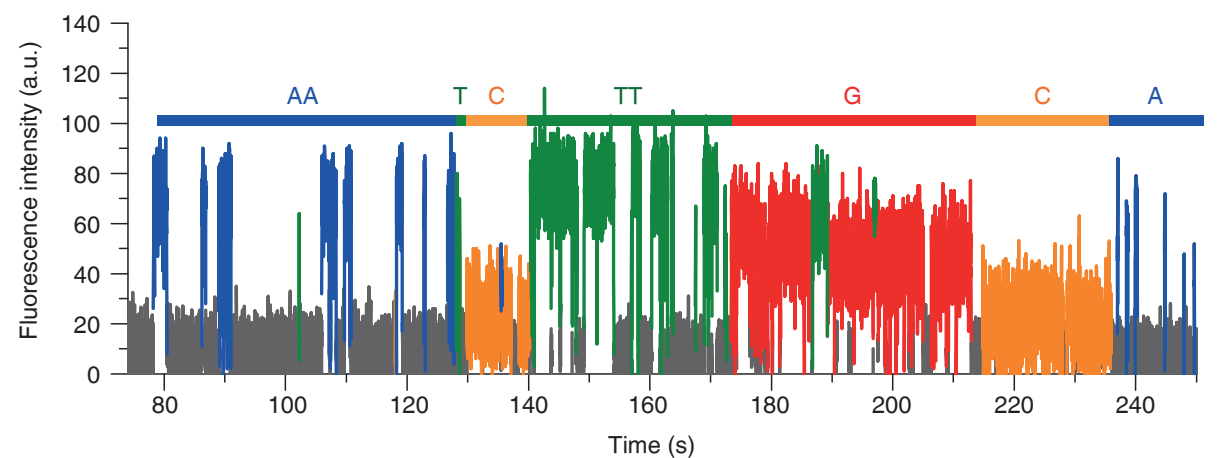

(b)

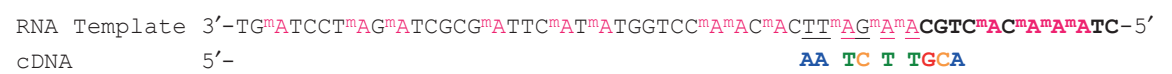

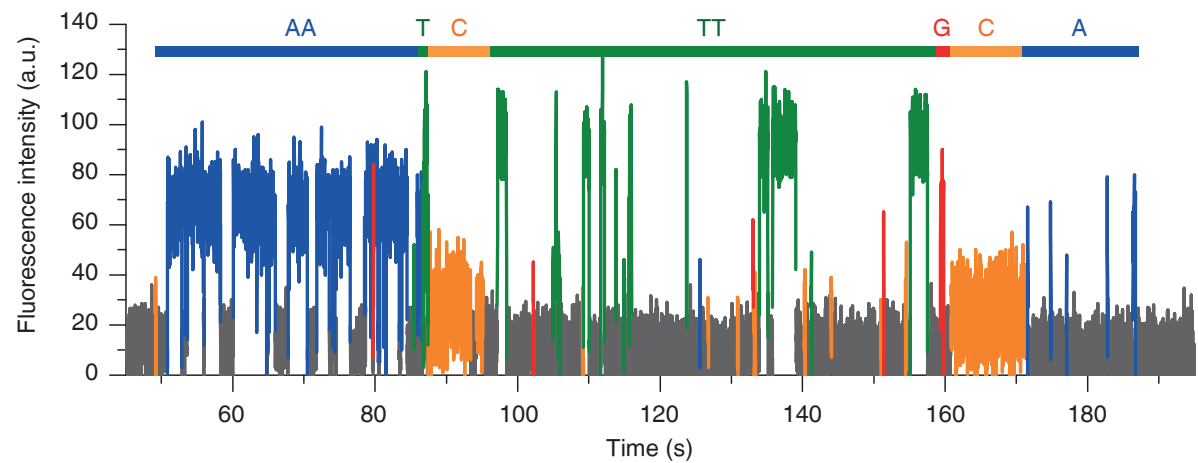

(c)

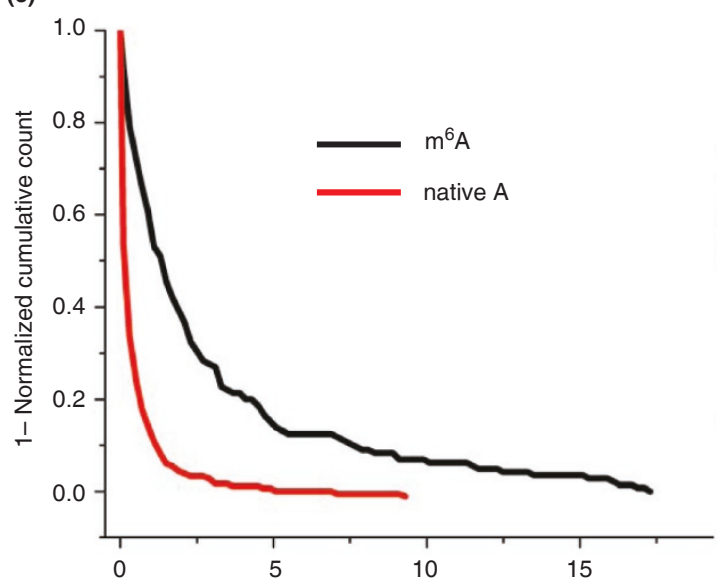

(d) 4

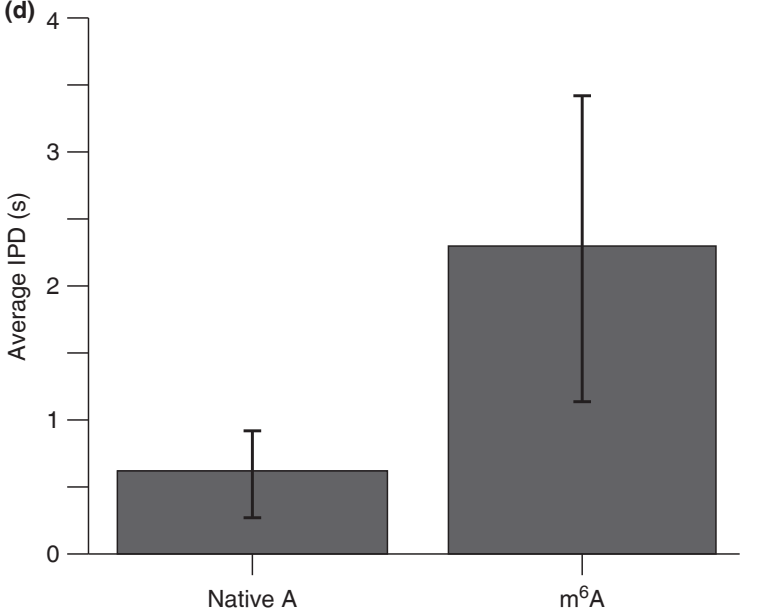

Figure 4. Single-molecule sequencing of RNA to detect epitranscriptomic changes. SMRT sequencing with the Pacific Biosciences RS shows longer times (inter-pulse distances) to incorporate $\mathrm{m}^{6} \mathrm{~A}$ versus standard adenosines. (a) Experimental design for using a DNA primer in a reverse transcription reaction. Sequencing of the unmodified template shows, in a single-molecule sequencing trace, base incorporation via a reverse transcriptase-mediated cDNA synthesis reaction. (b) Shows sequencing as with (a), but using an RNA template with $\mathrm{m}^{6} \mathrm{~A}$ instead of normal adenosines. Incorporation of thymines ( $\mathrm{T}$ ) show significant delay (longer inter-pulse distances). A.U. stands for normalized arbitrary units in fluorescence measurement. (c) Exponential fit of experimentally observed inter-pulse distances (IPDs). (d) Shows the difference between the average IPDs for native As and $\mathrm{m}^{6} \mathrm{As}$. The average IPD in each case is the reverse of the exponential decay rate. The error bars indicate the range around each average IPD that includes $83 \%$ of the observed IPDs (that is, $\pm 1 / 2$ of standard deviation of the exponential fit). We used an AnsariBradley test in Matlab to confirm that the distribution functions were different $(P=0.0043)$. 


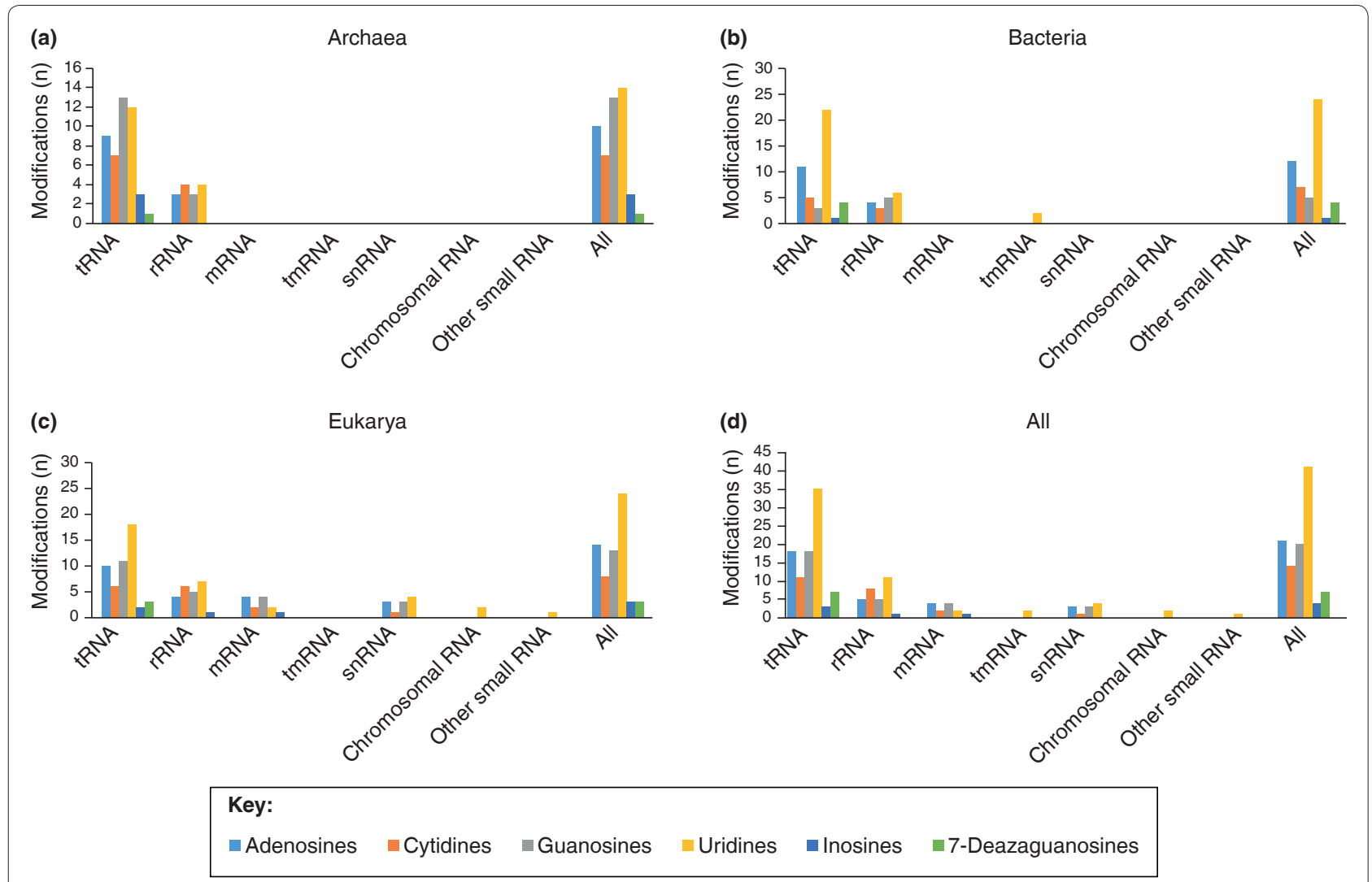

Figure 5. Known types of RNA modifications. Known modifications to RNA bases are grouped by RNA type, base and species: (a) archaea; (b) bacteria; (c) eukarya; (d) all species. Data are compiled from the RNA Modification Database [13].

summarize the catalog of known RNA modifications by species, RNA type and base (Figure 5) [13].

Interestingly, the enzyme commonly known as DNA methyltransferase-2 (DNMT2) [Swiss-Prot: O14717] was shown to methylate cytosine 38 of tRNA ${ }^{\text {Asp }}$ [49], and with such high specificity that it was renamed tRNA aspartic acid methyltransferase 1 (TRDMT1). More recently, two more tRNAs were found to be methylated by TRDMT1, and it was also observed that the methylation protects the tRNA from stress-induced cleavage and improves its stability $[50,51]$. Several tRNA nucleoside modifications have been shown to control frame shifting and codon binding during translation. These types of modifications often occur in the crucial 7 bp anticodon stem and loop (ASL) region that binds to mRNA codons in ribosomes, and are hypothesized to affect the stability and codon binding affinity during translation by controlling the overall shape of the loop and its dynamics [52-54]. Taken together, a pattern emerges in which RNA modifications in multiple RNA species act as a critical regulatory layer of RNA biology.

Many RNA modifications would benefit from a more global and cross-species characterization than is present in the existing literature. For example, studies in
Escherichia coli and yeast have shown that nucleotide modifications in rRNA lie in functionally significant regions, with a possible role in the regulation of translation [55]. Another example is methylation in plant rRNAs, where the modification is thought to help maintain rRNA stability, possibly in order to sustain ribosomal function during dramatic changes in temperature [56]. Interestingly, rRNA modifications in trypanosomes were shown to be mediated by small nucleolar RNAs (snoRNAs) [57], and changes in pseudouridylation of rRNA in mice, induced by mutations in DKC1 [SwissProt: Q9ESX5], led to the onset of dyskeratosis congenital, resulting in an increase in tumor susceptibility [58].

Taken together, these studies demonstrate the possible significance and functional importance of $(\mathrm{r} / \mathrm{t} / \mathrm{m} / \mathrm{mi} / \mathrm{sno} /$ linc)RNA modifications and begin to sketch out what might be called a transcriptomic regulome, where various species of coding and noncoding [59] RNAs, as well as their modified epitranscriptomic variants, compete with, coordinate and control each other during normal cellular processes, from the birth of a transcript until the production of its subsequent protein product or localization of its cellular target. 


\section{Conclusions}

Characterizations of $\mathrm{m}^{6} \mathrm{~A}$ across the transcriptome show that $\mathrm{m}^{6} \mathrm{~A}$ is present in the majority of mammalian genes, and is highly enriched at the beginning of the 3' UTR and near the stop codon. Yet, many peaks exist in intergenic regions or in introns, and there is some evidence that $\mathrm{m}^{6} \mathrm{~A}$ functions in the regulation of splicing or other modifications that take place in the processing of RNA into a mature transcript. Since $\mathrm{m}^{6} \mathrm{~A}$ distribution has already been shown to undergo developmental changes and differences in cancer cell lines, it is also possible that epitranscriptomic signatures may be used to stratify various states of disease, just as in epigenetics [60]. Despite these advances, the complete purpose and molecular function of $\mathrm{m}^{6} \mathrm{~A}$ is still unknown.

Nonetheless, some reasonable hypotheses can be proposed from the existing data. The enrichment of $\mathrm{m}^{6} \mathrm{~A}$ sites near the stop codon suggests that the modification could play some role in regulating translation termination, potentially by altering translation efficiency or ribosome occupancy. In addition, $\mathrm{m}^{6} \mathrm{~A}$ may mark transcripts for shuttling to RNA granules or for other mechanisms that will preserve the RNA for later use. Just as the number of known modifications of RNA has rapidly expanded (currently 107), the number of known RNAbinding proteins similarly keeps growing, and it is possible that some of these may be responsible for altering the function of $\mathrm{m}^{6} \mathrm{~A}$ within RNAs, either directly or through the regulation of FTO or METTL3. Such interactions could occur at any point of transcription, post-transcriptional modification or translation, with different consequences at each stage in the life of an mRNA. Finally, it is also possible that some RNA binding proteins may be $\mathrm{m}^{6} \mathrm{~A}$ site scanners that bind selectively to either methylated or unmethylated RNA, and as such would be regulated by the epitranscriptomic state of an RNA.

Two additional avenues warrant consideration when discussing possible regulatory functions of $\mathrm{m}^{6} \mathrm{~A}$. First, even though an inverse spatial relationship was observed between $\mathrm{m}^{6} \mathrm{~A}$ peaks and microRNA (miRNA) binding sites in 3' UTRs [19], it is notable that brain tissue is enriched for both highly expressed miRNAs and $\mathrm{m}^{6} \mathrm{~A}$ containing genes, which suggests that miRNAs might influence the methylation of a targeted mRNA. In addition, recent work has shown an interplay of mRNA methylation and the reduction of Dicer activity, thus decreasing miRNA maturation rates [61]. Second, $\mathrm{m}^{6} \mathrm{~A}$ has already been shown to inhibit RNA editing in certain cases [62], implying that $\mathrm{m}^{6} \mathrm{~A}$ may serve as the longsought balancing mechanism for the prevention of RNA editing [63]. If it is the case that $\mathrm{m}^{6} \mathrm{~A}$ prevents RNA editing from occurring, then evidence for this should be apparent in a diminished overlap between $\mathrm{m}^{6} \mathrm{~A}$ and the target RNA editing sites. So far, this appears to be true
[19], but the number of sites examined is too low to be definitive yet. If upheld with additional experiments, these feedback and regulatory loops may help explain the genesis and changes in RNA editing sites and miRNA levels, and provide additional mechanisms for controlling gene expression and RNA function.

In summary, the high-throughput and single-molecule methods described here represent the dawn of new research into a novel, RNA-based regulatory layer in cells, which adds yet another component of regulatory complexity to the central dogma of molecular biology (Additional file 5). The high conservation of specific $\mathrm{m}^{6} \mathrm{~A}$ sites across mouse and humans, as well as the general increase in PhyloP conservation scores of the $\mathrm{m}^{6} \mathrm{~A}$ sites themselves [19], both indicate that $\mathrm{m}^{6} \mathrm{~A}$ is under strong evolutionary selection pressure, and thus may represent a critical modification for many organisms. Even though previous evidence indicates that $\mathrm{m}^{6} \mathrm{~A}$ is an RNA modification present in all species, it has so far only been examined on a transcriptome-wide basis in two species (human and mouse), and observed in mRNAs only in eukaryotes, leaving open a wide area of research for many eukaryotic and prokaryotic systems. Just as the protein translation code and epigenetic code have slowly accreted into a cogent framework for information transfer and regulation within the cell, and between generations, these data indicate that an important epitranscriptome code is emerging. Notably, this dynamic code already appears to greatly expand the function and regulatory potential of all information contained within the many species of RNA present in a cell.

\section{Methods}

Sequence data were realigned to the genome using BWA [38], TopHat 2 [39] or GSNAP [40]. BWA was run using default parameters, and GSNAP and TopHat 2 were inputted with known RefSeq transcript definitions and run with novel splice junction finding turned on. The aligned files were converted to bam files using SamTools [64], filtering out reads with Phred quality scores under 20. BEDTools [65] was used to compute genome properties, such as coverageBed to compute genome coverage and RPKM (using a Perl script) and intersectBed to determine peak overlaps. Subsampling was accomplished using Picard's DownSampleSam [66].

Peak-finding was accomplished using MeRIPPeR [35] and transcriptome profile plots were generated using Jenotator: Java Genome Annotator [67]. A custom R script was used for plotting the transcriptome profile plot and Excel 2013 was used to plot the other bar charts. rmake was used to generate genome annotation plots [68]. Motif regions were extracted using ChIPseeqer's ChIPseeqerMotifMatch [69] and individual $\mathrm{m}^{6} \mathrm{~A}$ sites were extrapolated with a Perl script. 


\section{Additional files}

Additional file 1. Alignment of reads to various gene categories. The percentage of bases mapping to each category was plotted for three $\mathrm{m}^{6} \mathrm{~A}$ samples and three matching control samples from the MeRIP-seq study's human HEK293T dataset. The controls are samples sequenced prior to the IP and the high number of $3^{\prime}$ UTR reads represents control regions that do not contain $\mathrm{m}^{6} \mathrm{~A}$ peaks, as well as the fact that most peaks fall right between the last CDS and the beginning of the $3^{\prime} U T R$.

Additional file 2. Effect of aligner on peak detection. Realigning the MeRIP-seq HEK293T data using three different aligners, with MeRIPPeR as the peak caller, shows that the peak distribution is dependent on the aligner chosen. Using TopHat 2 increases the number of $5^{\prime}$ UTR peaks detected.

Additional file 3. Peak and transcript detection as a function of read depth. (a) Increasing the number of aligned reads sampled from three different aligners (BWA, GSNAP and TopHat 2) shows an increased peak detection (linear regression $R^{2}=0.83$ ). Reads were sampled from aligned reads of the MeRIP-seq HEK293T sample 2 dataset. (b) The number of transcripts that contain peaks for each of the subsampled levels. While increasing the read depth results in a dramatic increase in the number of peaks, the number of transcripts shows a much slower increase, indicating that increasing the read depth likely finds peaks with lower $\mathrm{m}^{6} \mathrm{~A}$ stoichiometry.

Additional file 4. Antibody peak distribution. Peak distribution shown across gene bodies for each individual antibody, with the SySy antibody shown as a solid line and the NEB antibody shown as a dashed line. The distributions suggest that the two antibodies produce similar binding profiles. The NEB antibody does show a slightly higher peak in the $5^{\prime}$ UTR for the HEK293T sample 3, but the sample is a separate biological replicate and there is no SySy run for comparison, so the distribution could also be attributed to some change in the biological sample itself.

Additional file 5. The increasing complexity of the central dogma of molecular biology. Top: the originally proposed central dogma, with unidirectional information flow. Bottom: the current view of the central dogma, wherein information content can flow backwards or sideways with RT, RNA-binding proteins (RbPs) and RNA editing. In addition, information can be copied within each of the three realms: genetic (blue) copying such as with transposable elements; transcriptional (red) copying with ribozymes and rich levels of RNA regulation using small RNAs (micro, piwi, si, viRNAs); and proteomic (green) copying using prions. Information can also move between generations or be transmitted between species, such as with epigenetic marks, viRNAs and prions (gray area below).

\section{Abbreviations}

FDR, false discovery rate; IP, immunoprecipitation; $\mathrm{m}^{6} \mathrm{~A}$, methyl-6-adenosine; MeRIP-seq, methylated RNA immunoprecipitation and sequencing; RPKM, reads per kilobase of exon model per million mapped reads; SMRT, singlemolecule real-time; UTR, untranslated region; ZMW, zero-mode waveguide.

\section{Competing interests}

YS, KM, SJ, and CEM declare that they have no competing interests. IDV and JK are full-time employees at Pacific Biosciences, a company commercializing single-molecule, real-time nucleic acid sequencing technologies.

\section{Acknowledgements}

We wish to acknowledge the invaluable contribution of the WCMC Epigenomics Core Facility. Supported by a Starr Cancer Consortium grant
(14-A442) (CEM, YS), National Institutes of Health grants 14-A411, 14-A442, and 1R01NS076465-02 (CEM) and NINDS NS56306 (SRJ), and the Tri-Institutional Training Program in Computational Biology and Medicine (YS).

\section{Author details}

'Department of Physiology and Biophysics, Weill Cornell Medical College, New York, NY 10065, USA. ${ }^{2}$ The HRH Prince Alwaleed Bin Talal Bin Abdulaziz Alsaud Institute for Computational Biomedicine, Weill Cornell Medical College, New York, NY 10065, USA. ${ }^{3}$ Tri-Institutional Training Program in Computational Biology and Medicine, New York, NY10065, USA. ${ }^{4}$ Department of Pharmacology, Weill Cornell Medical College, New York, NY 10065, USA. 5Pacific Biosciences, 1380 Willow Rd, Menlo Park, CA 94025, USA

Published: 31 October 2012

\section{References}

1. Brownlee GG, Sanger F, Barrell BG: Nucleotide sequence of 5S-ribosomal RNA from Escherichia coli. Nature 1967, 215:735-736.

2. Sanger F, Air GM, Barrell BG, Brown NL, Coulson AR, Fiddes JC, Hutchison CA, Slocombe PM, Smith M: Nucleotide sequence of bacteriophage phi X174 DNA. Nature 1977, 265:687-695

3. Johnson TB, Coghill RD: Researches on pyrimidines. C111. The discovery of 5-methyl-cytosine in tuberculnic acid, the nucleic acid of the tubercle bacillis. J Am Chem Soc 1925, 47:2838-2844

4. Wyatt GR, Cohen SS: A new pyrimidine base from bacteriophage nucleic acids. Nature 1952, 170:1072-1073.

5. Ryan L, Ecker JR: Finding the fifth base: genome-wide sequencing of cytosine methylation. Genome Res, 2009, 19:959-966.

6. Münzel M, Globisch D, Carell T: 5-Hydroxymethylcytosine, the sixth base of the genome. Angewandte Chemie International Edition 2011, 50:6460-6468.

7. Korlach J, Turner SW: Going beyond five bases in DNA sequencing. Cur Opin Struct Biol 2012, 22:251-261.

8. Miyanari Y, Torres-Padilla M-E: Control of ground-state pluripotency by allelic regulation of Nanog. Nature 2012,483:470-473.

9. Chadwick LH: The NIH Roadmap Epigenomics Program data resource. Epigenomics 2012, 4:317-324.

10. Blueprint Epigenome [http://www.blueprint-epigenome.eu]

11. Dai B, Rasmussen TP: Global epiproteomic signatures distinguish embryonic stem cells from differentiated cells. Stem Cells 2007, 25:2567-2574

12. Akalin A, Garrett-Bakelman FE, Kormaksson M, Busuttil J, Zhang L, Khrebtukova I, Milne TA, Huang Y, Biswas D, Hess JL, Allis CD, Roeder RG, Valk PJM, Löwenberg B, Delwel R, Fernandez HF, Paietta E, Tallman MS, Schroth GP, Mason CE, Melnick A, Figueroa ME: Base-pair resolution DNA methylation sequencing reveals profoundly divergent epigenetic landscapes in acute myeloid leukemia. PLoS Genet 2012, 8:e1002781.

13. Agris P, Crain P, Rozenski J, Fabris D, Vendeix F: The RNA Modification Database [http://rna-mdb.cas.albany.edu/RNAmods/]

14. Desrosiers RC, Friderici KH, Rottman FM: Characterization of Novikoff hepatoma mRNA methylation and heterogeneity in the methylated 5' terminus. Biochemistry 1975, 14:4367-4374.

15. Wei C-M, Gershowitz A, Moss B: Methylated nucleotides block 5 ' terminus of HeLa cell messenger RNA. Cell 1975, 4:379-386.

16. Moss B, Gershowitz A, Stringer JR, Holland LE, Wagner EK: 5'-Terminal and internal methylated nucleosides in herpes simplex virus type 1 mRNA. J Virol 1977, 23:234-239.

17. Bodi Z, Button JD, Grierson D, Fray RG: Yeast targets for mRNA methylation. Nucleic Acids Res 2010, 38:5327-5335.

18. Nichols JL: N6-methyladenosine in maize poly(A)-containing RNA. Plant SC Lett 1979, 15:357-361.

19. Meyer KD, Saletore $Y$, Zumbo P, Elemento O, Mason CE, Jaffrey SR: Comprehensive analysis of mRNA methylation reveals enrichment in 3' UTRs and near stop codons. Cell 2012, 149:1635-1646.

20. Dominissini D, Moshitch-Moshkovitz S, Schwartz S, Salmon-Divon M, Ungar L, Osenberg S, Cesarkas K, Jacob-Hirsch J, Amariglio N, Kupiec M, Sorek R, Rechavi G: Topology of the human and mouse $\mathrm{m}^{6} \mathrm{~A}$ RNA methylomes revealed by $\mathrm{m}^{6} \mathrm{~A}$-seq. Nature 2012, 485:201-206.

21. Clancy MJ, Shambaugh ME, Timpte CS, Bokar JA: Induction of sporulation in Saccharomyces cerevisiae leads to the formation of N6-methyladenosine in mRNA: a potential mechanism for the activity of the IME4 gene. Nucleic Acids Res 2002, 30:4509-4518. 
22. Iwanami Y, Brown GM: Methylated bases of ribosomal ribonucleic acid from HeLa cells. Arch Biochem Biophys 1968, 126:8-15.

23. Epstein $P$, Reddy $R$, Henning D, Busch $H$ : The nucleotide sequence of nuclear U6 (4.7 S) RNA. J Biol Chem 1980, 255:8901-8906

24. Desrosiers R, Friderici K, Rottman F: Identification of methylated nucleosides in messenger RNA from Novikoff hepatoma cells. Proc Nat Acad Sci U SA 1974, 71:3971-3975.

25. Levis R, Penman S: 5'-Terminal structures of poly $(A)+$ cytoplasmic messenger RNA and of poly $(A)+$ and poly $(A)$ - heterogeneous nuclear RNA of cells of the dipteran Drosophila melanogaster. J Mol Biol 1978, 120:487-515.

26. Wei CM, Gershowitz A, Moss B: 5'-Terminal and internal methylated nucleotide sequences in HeLa cell mRNA. Biochemistry 1976, 15:397-40

27. Bringmann P, Lührmann R: Antibodies specific for N6-methyladenosine react with intact snRNPs U2 and U4/U6. FEBS Lett 1987, 213:309-315.

28. Horowitz S, Horowitz A, Nilsen TW: Mapping of N6-methyladenosine residues in bovine prolactin mRNA. Proc Nat Acad Sci U S A 1984, 81:5667-5671.

29. Chen-Kiang S, Nevins JR, Darnell JE Jr: N-6-methyl-adenosine in adenovirus type 2 nuclear RNA is conserved in the formation of messenger RNA. J Mol Biol 1979, 135:733-752.

30. Beemon K, Keith J: Localization of N6-methyladenosine in the Rous sarcoma virus genome. J Mol Biol 1977, 113:165-179.

31. Kane SE, Beemon K: Precise localization of $\mathrm{m}^{6} \mathrm{~A}$ in Rous sarcoma virus RNA reveals clustering of methylation sites: implications for RNA processing Mol Cell Biol 1985, 5:2298-2306.

32. Jia G, Fu Y, Zhao X, Dai Q, Zheng G, Yang Y, Yi C, Lindahl T, Pan T, Yang Y-G, He $\mathrm{C}$ : N6-Methyladenosine in nuclear RNA is a major substrate of the obesityassociated FTO. Nat Chem Biol 2011, 7:885-887.

33. Benedict $C$, Jacobsson JA, Rönnemaa E, Sällman-Almén M, Brooks S, Schultes $B$, Fredriksson R, Lannfelt L, Kilander L, Schiöth HB: The fat mass and obesity gene is linked to reduced verbal fluency in overweight and obese elderly men. Neurobiol Aging 2011, 32:1159.e1-5.

34. Keller L, Xu W, Wang HX, Winblad B, Fratiglioni L, Graff C: The obesity related gene, $F T O$, interacts with $A P O E$, and is associated with Alzheimer's disease risk: a prospective cohort study. J Alzheimers Dis 2011, 23:461-469.

35. Saletore Y, Mason CE: MeRIPPeR [http://meripper.sourceforge.net/]

36. Rye MB, Sætrom P, Drabløs F: A manually curated ChIP-seq benchmark demonstrates room for improvement in current peak-finder programs. Nucleic Acids Res 2011, 39:e25.

37. Wilbanks EG, Facciotti MT: Evaluation of algorithm performance in ChIPSeq peak detection. PLoS One 2010, 5:e11471.

38. Li H, Durbin R: Fast and accurate long-read alignment with BurrowsWheeler transform. Bioinformatics 2010, 26:589-595.

39. Trapnell C, Pachter L, Salzberg SL: TopHat: discovering splice junctions with RNA-Seq. Bioinformatics 2009, 25:1105-1111.

40. Wu TD, Nacu S: Fast and SNP-tolerant detection of complex variants and splicing in short reads. Bioinformatics 2010, 26:873-881.

41. Hansen KD, Brenner SE, Dudoit S: Biases in Illumina transcriptome sequencing caused by random hexamer priming. Nucleic Acids Res 2010, 38:e131.

42. Harper JE, Miceli SM, Roberts RJ, Manley JL: Sequence specificity of the human mRNA N6-adenosine methylase in vitro. Nucleic Acids Res 1990, 18:5735-5741

43. Wei C-M, Moss B: Nucleotide sequences at the N6-methyladenosine sites of HeLa cell messenger ribonucleic acid. Biochemistry 1977, 16:1672-144. Elemento O, Slonim N, Tavazoie S: A universal framework for regulatory element discovery across all genomes and data types. Mol Cell 2007, 28:337-350.

45. Eid J, Fehr A, Gray J, Luong K, Lyle J, Otto G, Peluso P, Rank D, Baybayan P, Bettman B, Bibillo A, Bjornson K, Chaudhuri B, Christians F, Cicero R, Clark S, Dalal R, Dewinter A, Dixon J, Foquet M, Gaertner A, Hardenbol P, Heiner C, Hester K, Holden D, Kearns G, Kong X, Kuse R, Lacroix Y, Lin S, et al.: Real-time DNA sequencing from single polymerase molecules. Science 2009, 323:133-138.

46. Flusberg BA, Webster DR, Lee JH, Travers KJ, Olivares EC, Clark TA, Korlach J, Turner SW: Direct detection of DNA methylation during single-molecule, real-time sequencing. Nat Methods 2010, 7:461-465.

47. Song CX, ClarkTA, Lu XY, Kislyuk A, Dai Q, Turner SW, He C, Korlach J: Sensitive and specific single-molecule sequencing of 5-hydroxymethylcytosine. Nat Methods 2011, 9:75-77.
48. Wanunu M, Cohen-Karni D, Johnson RR, Fields L, Benner J, Peterman N, Zheng Y, Klein ML, Drndic M: Discrimination of methylcytosine from hydroxymethylcytosine in DNA molecules. J Am Chem Soc 2011, 133:486-492.

49. Goll MG, Kirpekar F, Maggert KA, Yoder JA, Hsieh C-L, Zhang X, Golic KG, Jacobsen SE, Bestor TH: Methylation of tRNA ${ }^{\text {Asp }}$ by the DNA methyltransferase homolog Dnmt2. Science 2006, 311:395-398.

50. Schaefer M, Pollex T, Hanna K, Tuorto F, Meusburger M, Helm M, Lyko F: RNA methylation by Dnmt2 protects transfer RNAs against stress-induced cleavage. Genes Dev 2010, 24:1590-1595.

51. Tuorto F, Liebers R, Musch T, Schaefer M, Hofmann S, Kellner S, Frye M, Helm M, Stoecklin G, Lyko F: RNA cytosine methylation by Dnmt2 and NSun2 promotes tRNA stability and protein synthesis. Nat Struct Mol Biol 2012, 19:900-905.

52. Urbonavièius J, Qian Q, Durand JMB, Hagervall TG, Björk GR: Improvement of reading frame maintenance is a common function for several tRNA modifications. EMBO J 2001, 20:4863-4873.

53. Agris PF: Bringing order to translation: the contributions of transfer RNA anticodon-domain modifications. EMBO Rep 2008, 9:629-635.

54. Dao V, Guenther R, Malkiewicz A, Nawrot B, Sochacka E, Kraszewski A Jankowska J, Everett K, Agris PF: Ribosome binding of DNA analogs of tRNA requires base modifications and supports the "extended anticodon". Proc Natl Acad Sci US A 1994, 91:2125-2129.

55. Decatur WA, Fournier MJ: rRNA modifications and ribosome function. Trends Biochem Sci 2002, 27:344-351.

56. Brown JW, Echeverria M, Qu LH: Plant snoRNAs: functional evolution and new modes of gene expression. Trends Plant Sci 2003, 8:42-49.

57. Liang X-H, Uliel S, Hury A, Barth S, Doniger T, Unger R, Michaeli S: A genomewide analysis of C/D and H/ACA-like small nucleolar RNAs in Trypanosoma brucei reveals a trypanosome-specific pattern of rRNA modification. RNA 2005, 11:619-645.

58. Ruggero D, Grisendi S, Piazza F, Rego E, Mari F, Rao PH, Cordon-Cardo C, Pandolfi PP: Dyskeratosis congenita and cancer in mice deficient in ribosomal RNA modification. Science 2003, 299:259-262.

59. Stolc V, Gauhar Z, Mason C, Halasz G, van Batenburg MF, Rifkin SA, Hua S, Herreman T, Tongprasit W, Barbano PE, Bussemaker HJ, White KP: A gene expression map for the euchromatic genome of Drosophila Melanogaster. science 2004, 306:655-660.

60. Akalin A, Garrett-Bakelman FE, Kormaksson M, Busuttil J, Zhang L, Khrebtukova I, Milne TA, Huang Y, Biswas D, Hess JL, Allis CD, Roeder RG, Valk PJ, Löwenberg B, Delwel R, Fernandez HF, Paietta E, Tallman MS, Schroth GP, Mason CE, Melnick A, Figueroa ME. Base-pair resolution DNA methylation sequencing reveals profoundly divergent epigenetic landscapes in acute myeloid leukemia. PLoS Genet 2012, 8:e1002781.

61. Xhemalce B, Robson SC, Kouzarides T: Human RNA methyltransferase BCDIN3D regulates microRNA processing. Cell 2012, 151:278-288.

62. Veliz EA, Easterwood LM, Beal PA: Substrate analogues for an RNA-editing adenosine deaminase: mechanistic investigation and inhibitor design. $J$ Am Chem Soc 2003, 125:10867-10876.

63. Li M, Wang IX, Li Y, Bruzel A, Richards AL, Toung JM, Cheung VG: Widespread RNA and DNA sequence differences in the human transcriptome. Science 2011, 333:53-58

64. Li H, Handsaker B, Wysoker A, Fennell T, Ruan J, Homer N, Marth G, Abecasis G, Durbin R: The sequence alignment/map format and SAMtools. Bioinformatics 2009, 25:2078-2079.

65. Quinlan AR, Hall IM: BEDTools: a flexible suite of utilities for comparing genomic features. Bioinformatics 2010, 26:841-842.

66. Picard [http://picard.sourceforge.net/]

67. Saletore Y, Mason C: Jenotator: Java Genome Annotator [http://jenotator. sourceforge.net/]

68. Zumbo P, Li S, Mason C: r-make [http://physiology.med.cornell.edu/faculty/ mason/lab/r-make/]

69. Giannopoulou E, Elemento O: An integrated ChIP-seq analysis platform with customizable workflows. BMC Bioinformatics 2011, 12:277.

70. Novocraft: Novoalign [http://www.novocraft.com/]

71. Langmead B, Trapnell C, Pop M, Salzberg S: Ultrafast and memory-efficient alignment of short DNA sequences to the human genome. Genome Biol 2009, 10:R25

doi:10.1186/gb-2012-13-10-175

Cite this article as: Saletore $Y$, et al.: The birth of the Epitranscriptome: deciphering the function of RNA modifications. Genome Biology 2012, 13:175 